\title{
Mystery or not? Quantum cognition and the interpretation of the fantastic in Neil Gaiman
}

\section{Ivan Čipkár}

Ivan Čipkár is a PhD candidate at Palacký University in Olomouc and his work has been published in the Moravian Journal of Literature and Film. His current interest lies mainly in the field of cognitive literary studies (theory of mind applied to fiction; phenomenology of reader response) and he concerns himself with the creation of a new concept of universals in narrative reception.

\begin{abstract}
The present paper describes a reader-response experiment focusing on the perception of the genre of the fantastic. It also proposes an update of the genre's structuralist definition to better conform to contemporary cognitive research. Participants answered questions relating to the interpretation of events and important symbols in a Neil Gaiman short story and were also asked if they considered the story "fantasy" or "realistic fiction." Tzvetan Todorov characterized the fantastic as a hesitation between the uncanny (realistic interpretation) and the marvelous (supernatural interpretation). Neil Gaiman, a popular contemporary author of genre fiction, has utilized this hesitation between psychological and supernatural explanations of his stories to great effect. The results show a consistently higher degree of enjoyment in readers who were aware of the dual interpretation and partook in the hesitation. This paper also introduces the concept of quantum cognition into literary theory and explains the benefit of using terminology from this discipline in a reader-response context. The findings of this study could be the first step towards a better understanding of the different ways in which readers cognitively approach the fantastic or genre in general.
\end{abstract}

The popularity of unrealistic fiction has been steadily on the rise for the past several decades. Various genres and sub-genres have sprung into existence to wide commercial success and, very often, critical acclaim, their readership becoming more varied and its influence on mainstream culture ever greater. Critical literary theory has also, from the time Tzvetan Todorov described the genre of the fantastic in structuralist terms, become more varied, venturing into new and exciting interdisciplinary spaces. Groundbreaking research in areas as diverse as cognitive science and quantum physics have created ripples of influence that reach even into the study of the humanities, giving impetus for walking down avenues of academic inquiry untrammelled before.

In the present paper, I propose a re-evaluation of the structuralist treatment of the fantastic 
on two main points, reflecting some of the more recent interesting scientific developments and applying the philosophical framework implied in them to consider their potential benefit for literary research. These include cognitive science (a broad umbrella discipline representing a burgeoning, yet still rather marginal, approach when it comes to the study of literature) and quantum cognition (a quite specific daring new theory with implications for psychology, statistics and other disciplines). I present a reader-response experiment using the work of one of the most popular contemporary writers of unrealistic fiction, the British author Neil Gaiman, to show how such theoretical frameworks can be utilized in critical inquiry into the genre (or mode) of the fantastic.

Let me begin with established structuralist theory. Tzvetan Todorov (1975, p. 33) defines the fantastic as a hesitation between a natural and supernatural explanation of unfolding extraordinary events:

In a world which is indeed our world, the one we know ... there occurs an event which cannot be explained by the laws of this same familiar world. The person who experiences the event must opt for one of two possible solutions: either he is the victim of an illusion of the senses, of a product of the imagination - and the laws of the world then remain what they are; or else the event has indeed taken place, it is an integral part of reality - but then this reality is controlled by laws unknown to us. ... The fantastic occupies the duration of this uncertainty.... The fantastic is that hesitation experienced by a person who knows only the laws of nature, confronting an apparently supernatural event (ibid., p. 25.

The text must oblige the reader to consider the world of the characters as a world of living persons and to hesitate between a natural or supernatural explanation of the events described ... [and the reader] will reject allegorical as well as 'poetic' interpretations (ibid., p. 33).

I would like to raise several issues with this definition. First, as is inherent in the structuralist approach, it presupposes a particular kind of reader response based on an idealized reader. What may look extraordinary, singular and shocking to some readers may leave others unfazed. To push this point even further, could a ghost story be regarded as fantastic if the reader actually believes in the existence of ghosts in the real world?

Secondly, as many strict cognitivists would point out (Holland 1992), this and other similar definitions attribute agency to the text-see expressions such as: "the text must oblige the reader 
to hesitate...”. What if I choose to ignore the supposedly supernatural element in the text or opt out of the decision process altogether? How does the text oblige me not to? Attribution of agency to a text can be a useful abstraction, but we should keep in mind that it is nothing more than that - an abstraction. I argue that these and other ambiguities can be resolved by a strict focus on the reader and the processes that play into their reception of the literary work.

If we utilize Todorov's definition of the fantastic as genre definition in its strictest sense, we are inevitably left with an extremely limited number of works - a fact that Todorov himself is well aware of, so he broadens the category to encompass more than the liminal genre of the true fantastic. The hesitation that is crucial for the domain of the fantastic tends to be resolved in favour of either the supernatural or natural. Then we find ourselves in the domain of the marvelous or the uncanny, defined by Todorov (1975) thus:

"[In the uncanny], events are related which may be readily accounted for by the laws of reason, but which are, in one way or another, incredible, extraordinary, shocking, singular, disturbing or unexpected.” (p. 46)

"If we move to the other side of that median line which we have called the fantastic, we find ourselves in the fantastic-marvelous, the class of narratives that are presented as fantastic and that end with an acceptance of the supernatural." (p. 52)

As we can see, there is space left for the reader to decide which reading to adopt-marvelous or uncanny - and a question of degree arises: how far is the reader willing to go one way or another? Thus the concept of the genre is problematized in practice, should we use the abovementioned two modes as classifiers. Genre-based division is certainly an important guideline in areas such as book retail, where customers need to orient themselves. Neil Gaiman (2008) proposed a definition of genre that sounds almost cognitivist, as it stresses the role of the reader (audience), at the Julius Schwartz Lecture at MIT: "[genre contains things] that if they weren't there, you, as a member of an audience, would feel cheated. You've gone to a musical and nobody sings - what kind of musical is this? ... If you take out the gunfights from a western, then you don't have the thing there that the person came to see. . . If the plot is a machine that allows you to get from set piece to set piece, and the set pieces are things without which the reader or the viewer would feel cheated, then, whatever it is, it's genre. . . Subject matter doesn't make genre."

If we are to decide whether readers feel cheated or not by the absence of some expected elements, we ought to ask them. We need to examine how readers actually experience the 
hesitation between the uncanny and the marvelous, and how they decide (if they decide) to adopt one of the two interpretations, or, alternatively, opt to leave the experience unresolved and stay in the mode of the true fantastic.

I have conducted a reader-response experiment using a short story written by Neil Gaiman himself. I was interested in whether the participants enjoyed it, and tried to identify the factors that added or detracted from their enjoyment. Norman Holland (2009, p. 238) claims enjoyment stemming from "making sense" of the literary reality is one of the primary and defining motivations of the literary experience: "Being able to make sense of the imaginary world of a work of literature also confirms me in my characteristic way of making sense of my own everyday world, and that feels good. It gives me a sense of mastery and being in control." It follows from Holland's argument that enjoyment can serve as the most valuable gauge for all other cognitive processes that play into the reading experience.

Another important issue I focused on was perception of genre. Was there any hesitation experienced because of a supernatural element and, if so, was it resolved? Understanding the story as "fantasy" or "realistic fiction" (in Todorov's terms: marvelous or uncanny) was crosschecked by the participants' interpretation of two prominent items/symbols crucial to the plot: the gargoyle and the flower.

The participants included 16 females and 14 males aged 19-35, mostly speakers of English of $\mathrm{C} 1$ level and higher who were either college students (graduate and undergraduate) or had a college degree. All of them were active readers and seven of them were familiar with Gaiman's other works.

The story used for the experiment, "How Do You Think It Feels," (Gaiman 2005) is a firstperson narrative of a man having an extramarital affair with a younger woman, Becky. When he finally decides to leave his wife and children for his lover, Becky breaks up with him. The narrator suffers a mental breakdown and in his desperation creates a figurine of a gargoyle from Becky's plasticine. After the break-up, he lives a successful but empty life, shielded from emotions, until he and Becky meet again after many years. Spending the night with her, having an ominous dream vision of the gargoyle coming out of his chest and then disappearing back inside, gripping long black hair (presumably Becky's), he eventually finds himself alone in bed, feeling a complete emotional blank, a flower resembling an orchid lying next to him.

Reviewing the responses of the participants yielded two prominent interpretive branches. In the first one, the readers opted for a symbolic understanding or psychological explanation of the gargoyle, stating that it stood for "love turned hate," "an artificially/semi-consciously created defensive mechanism tinged with a strongly repressed sexual desire" or "[the 
protagonist's] emotional and sexual involvement with women he's not 'supposed' to be with, but at the same time he wants to" or that it was "a talisman intended to protect the narrator from pain; in the end proving too effective."

In what I identified as the other interpretive branch - the fantasy or marvelous reading - the readers understood the gargoyle to be some magical "protection against the beautiful woman that almost ruined his life," and "the narrator's resentment and hurt jealousy made real," that is, "a literal creature who lives inside the man's chest."

Responses pertaining to the flower were correspondingly distributed: on one hand, there were responses claiming "the flower itself can ... perhaps symbolize [Becky's] expression of being 'ready' for such a relationship, a strange expression of matured love . .." or that the flower "was probably left there by Becky, so that the main character would never forget about her, as she was probably never coming back." While even in this category of responses there was quite a variation as to Becky's attitude, the crucial point is their distinctiveness from the responses claiming the flower was in fact "the girl because the gargoyle took her" or that it was "Becky's sexual organs - the only thing that the demon left [the protagonist] to enjoy." Another less magical but still quite supernatural explanation read: "I think it could mean that Becky was trying to leave in the middle of the night—leaving a flower before sneaking out. That could explain why the gargoyle ate her."

To summarize, some readers understood the gargoyle as a purely symbolic device or a phantasm that could be explained by the psychological state of the protagonist. For them, the flower was mostly an unimportant detail with at most symbolic significance that could maybe tell us something about Becky's attitude. These readers opted for the realistic reading and if they had experienced any hesitation as to the supernatural elements, they resolved it in a way that rendered the story "uncanny." A substantial subgroup here disregarded the supernatural quality altogether and read the story as realistic fiction.

The other group registered the supernatural element and resolved the ambiguity of the story by accepting the gargoyle and sometimes even the orchid as elements of a magical or otherwise reality-transgressing narrative, opting for the marvelous interpretation. Still others simply remained undecided.

When asked, the first group claimed with confidence that the character of Becky remained alive - she was never in any real peril in the realistic interpretation after all - while the others argued there was satisfactory evidence that the gargoyle had indeed devoured, snatched and dragged into the protagonist's chest, or otherwise disposed of, Becky. The handful of respondents familiar with Gaiman's other works noted that it was probably the author's 
intention to create this ambiguity of interpretation and thus both scenarios were viable.

This kind of toying with the reader's sense of what is real, what is magical and what is imagined is indeed a staple of Neil Gaiman's work, the bulk of which makes use of a tension between the mundane and the magical, the everyday and the weird, which arguably leaves readers with a sense of wonder. Gaiman takes mythological or fairytale motifs and puts them into new contexts and reinterprets them in a way that make them feel relevant and close to our day-to-day experience. The remarkable popularity of his books is a testament to the effect his style has on readers and it makes for a worthwhile subject to explore in a reader-response context.

The other important point I focused on in the survey was the subjective enjoyment reported by the participants. The greatest number of respondents who reportedly did not enjoy the story was among those who opted for a realistic reading. Here, their enjoyment seemed to be strongly predicted by the degree of emotional investment in the characters that had to do with identification, empathy and finding projection space for their fantasies. Other than that, readers interpreting the story as "fantasy" enjoyed it comparatively more, and the apparently greatest self-reported enjoyment was tied to the awareness of the ambiguity or multiplicity of the interpretations.

Ultimately, the decision most readers faced was between two mutually exclusive outcomes: with Becky dead or otherwise seriously imperiled or Becky being alive and unharmed. There is always the position of opting out of the whole conundrum, but if the possibilities readers "find" in the text are to be realized, we are still left with the question: is Becky dead, or is she alive? The "most correct" answer to it seems to be a simple "yes."

In other words, I argue that the most engaging option is to reflect the hesitation inherent in the decision by admitting that Becky is both dead and alive at the same time, just as the story is both realistic (uncanny) or fantastic (marvelous). Here, a philosophical framework borrowed from quantum physics may be instructive.

Principles such as Heisenberg's uncertainty principle or the phenomenon of superposition of quantum particles are among the developments in natural sciences that have reverberated throughout our wider cultural context, including areas such as art or sociology. Their applicability in the humanities has always appeared rather far-fetched and contrived, but the latest developments in a new field called quantum cognition may change all that:

Quantum cognition is a new research program that uses mathematical principles from quantum theory as a framework to explain human cognition, including 
judgment and decision making, concepts, reasoning, memory, and perception . . . it uses quantum theory as a fresh conceptual framework and a coherent set of formal tools for explaining puzzling empirical findings in psychology. (Busemeyer and Wang, 2015, p. 163)

In their introduction, Wang and Busemeyer show how quantum theory can be relevant to the field of psychology. One of their main points concerns the principle of superposition and how it pertains to decision-making. Traditionally, the decision-making process (such as the reader's decision whether the story portrays realistic or supernatural events, if Becky is alive or dead) has been viewed to be guided by accumulation of evidence, as described by Markov random walk (MRW) theory: "According to MRW models, when deciding between two hypotheses, the cumulative evidence for or against each hypothesis realizes different levels at different times to generate a single particle-like trajectory of evidence levels across time. At any point in time, the decision-maker has a definite level of evidence, and choices are made by comparing the existing level of evidence against a criterion.” (Kvama et al., 2015, p. 10645)

However, as the authors of the paper point out, empirical evidence has disproved the notion that decision-making really works according to this model, pointing out that it "is inconsistent with the well-established idea that preferences and beliefs are constructed rather than revealed by judgments and decisions." Instead, they propose (ibid.) a quantum random-walk model, where "at any point in time before a decision, the decision-maker is in a superposition state that is not located at a single level of evidence. Instead, each level of evidence has a potential to be expressed, formalized as probability amplitude. New information changes the amplitudes, producing a wavelike process that moves the amplitude distribution across time."

How is this pertinent to the literary problem at hand? Reader's perception of the fictional state of Becky in the story can be likened to a veritable Schrödinger's cat that is objectively both dead and alive until we take a look at her, wherefore only one of the states becomes part of our reality. If the readers are aware of the two mutually exclusive interpretations and consider the respective evidence for each, they are presumably brought into a state of hesitation that may or may not be resolved by an eventual decision.

We can liken "meaning" to a state of, say, an electron or a photon. It is, in a manner of speaking, nowhere and everywhere at once, superposed with itself, and these positions can be characterized by a degree of probability. Thus, while the interpretations that Becky has left of her own volition or that she was destroyed by the magical creature seem likely, the idea that she was an alien lifeform from outer space that can metamorphose itself into a flower does not; 
yet it is not utterly inconceivable that some reader somewhere might come up with such an idea or that Gaiman was thinking this or any such outlandish thought to himself all along as a kind of personal joke.

Until (and if at all) the act of interpretation disposes of all other options, they are free to interfere with one another in spite of their logical incompatibility just as the superimposed photon interferes with the other "alternative" versions of itself. This interference results in paradoxical situations in physics, such as light behaving both as wave and as particles at the same time; in the case of a story written in the mode of the fantastic, the result is a state of hesitation that is somehow connected with reader's enjoyment and which constitutes the core identifying principle of the genre of the fantastic. This principle is of course not limited to the liminal genre of the fantastic or to any kind of duality, but it is this duality that serves as a most transparent demonstration of the principle, akin to Schrödinger's thought experiment with the two mutually exclusive yet simultaneously valid states of the unfortunate feline, used as a demonstration of the paradoxes which arise when we try to apply the conclusions of quantum laws to our macroscopic world.

I am not in any way implying that quantum physics is the cause of any of the properties of the thought processes or belief system of a reader, just as Wang and Busemeyer do not imply that the human brain is a quantum computer. Their (and my) proposal is quite modest: to look at some broad theoretical principles from quantum physics and, if supported by empirical evidence, use them as an inspiration for a re-evaluation of the way we think about our cognitive processes - decision-making broadly speaking and, as I propose in this article, on a more specific level, genre interpretation and other feedback in a reader response context.

Let me propose a redefinition of the fantastic, adding the cognitive and quantum twist to Todorov's original formulation. According to my findings, hesitation inherent in the superposition of the interpretations of the fantastic coincides with greater enjoyment of the story. Recalling the words of Norman Holland (2009, p. 333) that the core reason we read literature is because we simply enjoy it, we can postulate enjoyment of the tension arising from hesitation to be the main defining characteristic of the genre. The necessary prerequisites of the fantastic could then be summarized as follows:

1. The reader attends to a presumably supernatural element;

2. The element is understood to be able to change the significance of other important aspects of the story, leading to a plurality of mutually exclusive interpretations;

3. The reader interacts with the plurality by a way of hesitation between superposed; scenarios, some of which violate the laws of nature and some of which leave them intact. 
This set of three rules views the concept of genre as a set of reader's assumptions and mindsets that influence their enjoyment of the text. In this conception, the fantastic is then not a structural feature of the text but a state of mind reliant on a decision-making process where all possible options have some potential for being expressed.

Whether there even is such a thing as objective meaning external to the human mind is a long-standing, unresolved philosophical problem that I could not have properly pursued within the constraints of this paper (for example, see Descombes 2001). For the sake of argument let as assume that there is an external meaning which is somehow revealed in the physical reality of the characters on a printed page or a screen (which is hardly a controversial assumption to make since most of twentieth-century literary theory takes it for granted) and, taking the phenomenological approach, we should be able to reconstitute something about this external "truth" from our own perception of its form. This reconstitution should ideally result in a field of possibilities with no strictly delineated border, so there are no invalid interpretations but, rather, as in quantum probability, statistically irrelevant ones.

However, just as in physics we are unable to observe quantum phenomena directly without ruining the experiment (direct observation amounts to interference), we are similarly unable to directly answer the question of "what does the text really mean?" without our own cognitive interference, that is, interpretation, which irrevocably ruins the elusive artistic truth. We have then no other option than to look at the consequences of the phenomena that we cannot study directly. With no direct window into the human mind there is currently only one technique (barring rather crude means of monitoring, such as fMRI of blood flow in the brain) that is functional enough for this purpose: reader response.

The task of a cognitive reader-response theoretician then would be to consider which indicators in readers' reactions to focus on and how to interpret their bearing on the intersubjective reality reconstituted from the textual phenomena of the story. In the case of the fantastic, examining the varying degrees of self-reported enjoyment seemed to contribute towards the goal of defining the genre in terms of its effect.

\section{Works cited:}

Busemeyer, J. R., Z. Wang. 2015. What Is Quantum Cognition, and How Is It Applied to Psychology? In Current Directions in Psychological Science, vol. 24, no. 3, p. 163-169.

Descombes, V. 2001. The Mind's Provisions: A Critique of Cognitivism. New Jersey: Princeton University Press.

Gaiman, N. 2008. The Julius Schwartz Lecture at MIT. Cambridge: Comparative Media Studies program at MIT. Available at: 〈https://www.youtube.com/watch?v=KU-tncC7qIw>

Gaiman, N. 2005. How Do You Think It Feels? In: Smoke and Mirrors. London: Review. 
Holland, N. N. 1992. The Critical I. New York: Columbia University Press.

Holland, N. N. 2009. Literature and the Brain. Gainesville: The PsyArt Foundation.

Kvama, P. D., T. J. Pleskac, S. Yu, and J. R. Busemeyer. 2015. Interference effects of choice on confidence: Quantum characteristics of evidence accumulation. In Proceedings of the National Academy of Sciences of the United States of America, vol. 112, no. 34, p. 10645-10650.

Todorov, T. 1975. The Fantastic: A Structural Approach to a Literary Genre. New York: Cornell University Press.

Ivan Čipkár

Department of English and American Studies

Philosophical Faculty

Palacký University, Olomouc

Křǐkovského 10

77148 Olomouc

Czech Republic

ivan.cipkar01@upol.cz 